\title{
Closed pulmonary valvotomy in infants under 6 months of age: report of 14 consecutive cases without mortality
}

\author{
SIMCHA MILO, ALON YELLIN, ARAM SMOLINSKY, \\ LEONARD C BLIEDEN, HENRY N NEUFELD, AND DANIEL A GOOR
}

From the Department of Thoracic and Cardiovascular Surgery and The Heart Institute, The Sheba Medical Centre, Tel-Hashomer, and Sackler School of Medicine of Tel-Aviv, Tel-Aviv, Israel

ABSTRACT Fourteen infants, all under 6 months of age, underwent surgery for the relief of severz valvar pulmonary stenosis. A modified Brock (transinfundibular valvotomy) procedure wa\$ performed in all cases. Dilatation of the pulmonary valve with a mosquito clamp and biliar $\vec{f}^{3}$ dilator is the basis of the modified operation. All infants survived the operation. In two patients? there is residual, significant pulmonary stenosis, and in two additional cases pulmonary regurgitation $\overrightarrow{0}$ is present.

Transinfundibular (conal) pulmonary valvotomy is a technique devised by Brock $^{1}$ (1948) to achieve the opening of a stenotic pulmonary valve without the need for cardiopulmonary bypass.

In our experience this technique, with minor modifications, is very effective in the management of critical isolated valvar pulmonary stenosis in infants. In this report we present our experience with the Brock valvotomy in 14 infants under six months of age.

\section{Patients and methods}

All patients were operated on by the same team and this series includes our total experience with infants under 6 months of age who had isolated pulmonary valve stenosis. Between May 1973 and July 1977, 15 infants suffering from pulmonary valvar stenosis with normal aortic root were catheterised at the Heart Institute, Tel-Hashomer Hospital. Fourteen of these patients were operated on and form the basis of this report. The fifteenth patient, who was in good general condition, was catheterised at noon and was scheduled for operation the next morning. At midnight, however, this infant suddenly suffered a cardiac arrest and died.

There were eight males and six females. The

Address for reprint requests: Professor DA Goor, Department of Thoracic and Cardiovascular Surgery, The Sheba Medical Centre, Tel-Aviv, Israel. age range at the time of operation was one days to six months (table 1). All patients had simples isolated pulmonary valve stenosis with a normaहै aortic root and intact ventricular septum.

Clinical cyanosis was present in 11 of the patients, indicating that the foramen ovale was patent.

Eight patients underwent cardiac catheteris? ation and were operated on as emergency cases Three of these were in a preterminal condition? four were in respiratory distress, and one waš tachypnoeic, but with no distress. In the remainingo six patients the indication for surgery was as follows: severe cyanosis in four infants (cases 40 $5,10,12)$ and the presence of right ventricular pressure greater than systemic with evidence of right ventricular strain on the electrocardiogram in three (cases 9, 12, 13). We believe that these. patients are candidates for sudden death. The non-emergency cases were operated on within 24 hours of heart catheterisation. Additionat reievant catheterisation and clinical data ares presented in table 1 .

\section{Operative technique}

On the instrument table there were two syringesc each containing $50 \mathrm{ml}$ of blood and syringes of isoprenaline, adrenalin, and sodium bicarbonate? In the event of bradycardia or bleeding, replace $\stackrel{\mathbb{}}{\mathscr{2}}$ ment of blood or injection of medication was b immediate bolus dosage during the operation 
Table 1 C'linical laboratory and operative features in 14 infants with pulmonary stenosis

\begin{tabular}{|c|c|c|c|c|c|c|c|c|c|c|c|}
\hline $\begin{array}{l}\text { Case } \\
\text { number }\end{array}$ & Age & Sex & $\begin{array}{l}\text { Date of } \\
\text { operation }\end{array}$ & $\begin{array}{l}\text { Clinical } \\
\text { cyanosis }\end{array}$ & $\begin{array}{l}\text { Arterial } \\
\text { oxygen } \\
\text { saturation }\end{array}$ & $\begin{array}{l}\text { Clinical } \\
\text { condition }\end{array}$ & $\begin{array}{l}\text { Systolic } R V \\
\text { pressure } \\
(\mathbf{m m} \text { hg })\end{array}$ & $\mathrm{CHF}$ & $E C G$ & $\begin{array}{l}\text { Type of } \\
\text { valvotomy }\end{array}$ & Result \\
\hline 1 & 6 days & $\mathbf{M}$ & 18.7 .73 & $2+$ & 76 & Pret & 140 & - & RVH & TUBBS & Residual PS \\
\hline 2 & 6 months & $\mathbf{F}$ & 9.12 .73 & $2+(\mathrm{TI})$ & 53 & RD & 120 & - & RVH & TUBBS (18 mm) & \\
\hline 3 & 4 months & $\mathbf{F}$ & 12.12 .74 & $3+$ & 51 & RD & 90 & + & RVH & MC & Residual PS \\
\hline 4 & 6 weeks & $\mathbf{M}$ & 5.1.75 & $1+$ & 91 & Good & 100 & - & RVH & $\mathrm{MC}+\mathrm{BD}(9 \mathrm{~mm})$ & Good \\
\hline 5 & 5 months & $\mathbf{M}$ & 15.4 .75 & $1+$ & 91 & Good & 100 & - & RVH & $\mathrm{MC}+\mathrm{BD}(8 \mathrm{~mm})$ & Good \\
\hline 6 & 12 days & $\mathbf{F}$ & 20.8 .75 & $3+(\mathrm{TI})$ & 51 & $\begin{array}{l}\text { Tachy- } \\
\text { pnoea }\end{array}$ & 160 & + & RVH + LVH & $\mathrm{MC}+\mathrm{BD}(8 \mathrm{~mm})$ & PI \\
\hline 7 & 1 day & $\mathbf{M}$ & 12.9.75 & $3+(\mathrm{TI})$ & - & Pret & - & + & RVH + LVH & $\mathrm{MC}+\mathrm{BD}(7 \mathrm{~mm})$ & Good \\
\hline 8 & 30 days & $\mathbf{F}$ & 7.5 .76 & $2+$ & 78 & RD & 110 & - & RVH & $M C+B D(7 \mathrm{~mm})$ & Good \\
\hline 9 & 5 months & $\mathbf{F}$ & 16.6 .76 & 0 & 97 & Good & 160 & - & RVH + RVS & $M C+B D(8 \mathrm{~mm})$ & Good \\
\hline 10 & 6 months & $\mathbf{M}$ & 7.9 .76 & + & 90 & Good & 140 & - & RVH + RVS & $\mathrm{MC}+\mathrm{BD}(9 \mathrm{~mm})$ & Good \\
\hline 11 & 1 day & $\mathbf{M}$ & 11.11 .76 & $3+(\mathrm{TI})$ & - & Pret & 100 & + & RVH & $\mathrm{MC}+\mathrm{BD}(10 \mathrm{~mm})$ & Good \\
\hline 12 & 30 days & $\mathbf{M}$ & 23.1.77 & 0 & 97 & Good & 160 & - & RVH & $\mathrm{MC}+\mathrm{BD}(9 \mathrm{~mm})$ & Good \\
\hline 13 & 4 months & $\mathbf{F}$ & 17.3 .77 & $\mathbf{0}$ & 97 & Good & 140 & - & RVH + RVS & $\mathrm{MC}+\mathrm{BD}(9 \mathrm{~mm})$ & Good \\
\hline 14 & 4 days & $\mathbf{M}$ & 15.7 .77 & $3+$ & - & $\mathbf{R D}$ & 160 & - & RVH & $\mathrm{MC}+\mathrm{BD}(7 \mathrm{~mm})$ & Good \\
\hline
\end{tabular}

Pret = preterminal; $\mathbf{R V H}=$ right ventricular hypertrophy; $\mathrm{RVS}=$ right ventricular strain; $T I=$ tricuspid insufficiency; LVH =left ventricular hypertrophy; $\mathbf{R D}=$ respiratory distress; $\mathbf{M C}=$ mosquito clamp; $\mathbf{C H F}=$ congestive heart failure; $\mathrm{PS}=$ pulmonary stenosis; $\mathrm{PI}=$ pulmonary regurgitation; $\mathbf{B D}=$ biliary dilator.

Ventilation was with $100 \%$ oxygen and anaesthesia was with intravenous neuroleptics and curare. Except for two infants (cases 1 and 3), all patients were extubated at the end of the procedure.

In the first three cases the operative technique differed from the remaining 11 cases. In the first two, a small Tubbs dilator was inserted in the infundibulum about $1.5-2 \mathrm{~cm}$ proximal to the valve, and the valvotomy was performed with the dilator. The procedure was traumatic and awkward and this technique has since been abandoned. In the third case, valvotomy was performed with the aid of a mosquito clamp only. It was felt that this procedure was also inadequate, and the procedure was performed as follows in identical fashion in the other patients (fig 1).

The chest was opened transversely across the sternum. A square pursestring suture was inserted in the infundibulum just below the pulmonary valve. The myocardium was stabbed and a mosquito clamp was inserted with a thrust into the pulmonary artery. Initial dilatation was achieved by opening the mosquito clamp. Biliary dilators up to size $8-9 \mathrm{~mm}$ were subsequently inserted into the pulmonary artery. After each dilatation, (beginning with $4 \mathrm{~mm}$ ) the blood lost $(5-8 \mathrm{ml})$ was replaced as a bolus. In three cases $(6,7,12)$ manual cardiac massage for $30-40$ minutes was necessary. Each of these patients, however, was well enough to be extubated at the end of the operation.

Twelve patients were discharged between five and 10 days after the operation but patients 1 and 3 remained in hospital. There were no major postoperative complications.

\section{Follow-up}

The follow-up of the 14 patients was from 12 to 60 months (mean 40 months) (table 2).

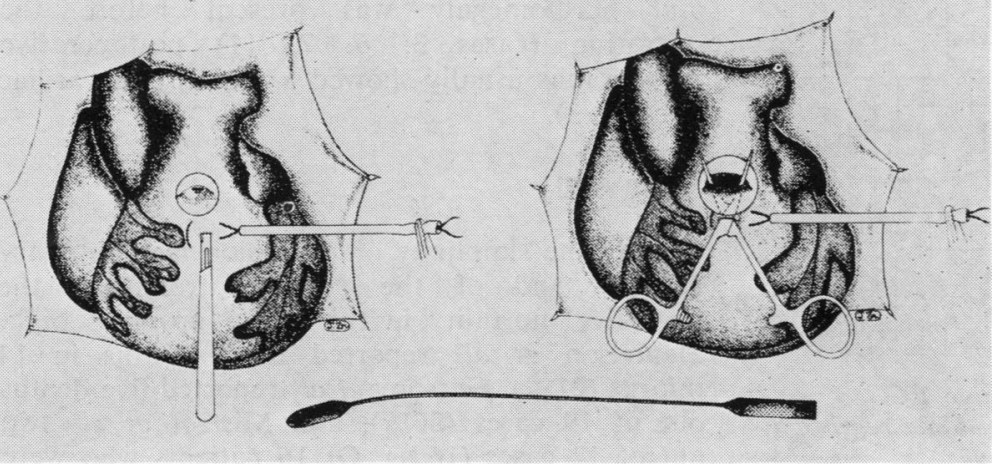

Fig 1 Diagrammatic illustration of the operation technique. Left: purse-string suture in the right ventricular outflow tract. Right: insertion of the clamp through the pulmonary valve and initial dilatation. Below: a biliary dilator used for further dilatation. 
Table 2 Postoperative follow-up data in 14 infants

\begin{tabular}{|c|c|c|c|c|c|}
\hline $\begin{array}{l}\text { Case } \\
\text { number }\end{array}$ & $\begin{array}{l}\text { Duration of } \\
\text { follow-up (mo) }\end{array}$ & $\begin{array}{l}\text { Residual significant } \\
\text { pulmonary stenosis }\end{array}$ & $\begin{array}{l}\text { Pulmondary } \\
\text { regurgitation }\end{array}$ & $\begin{array}{l}\text { Significant regression } \\
\text { of } R V H \text { in } E C G\end{array}$ & $\begin{array}{l}\text { Preoperative } \\
\text { cardiomegaly }+\mathrm{CHF}\end{array}$ \\
\hline 1 & 60 & + & - & - & - \\
\hline 2 & 58 & - & + & + & - \\
\hline 3 & 45 & + & - & - & + \\
\hline 4 & 44 & - & - & + & - \\
\hline 5 & 41 & - & - & + & - \\
\hline 6 & - & - & + & NF & + \\
\hline 7 & 35 & -- & - & + & + \\
\hline 8 & - & - & - & NF & - \\
\hline 9 & 25 & - & - & + & - \\
\hline 10 & - & - & - & NF & - \\
\hline 11 & 20 & - & - & + & + \\
\hline 12 & 19 & - & - & + & - \\
\hline 13 & 16 & - & - & + & - \\
\hline 14 & 12 & - & - & + & - \\
\hline
\end{tabular}

$\mathrm{RVH}=\mathrm{Right}$ ventricular hypertrophy $\mathbf{C C F}=$ congestive cardiac failure; $\mathrm{NF}=$ no follow-up.

Three patients (cases $6,8,10$ ) were examined in the early postoperative period and have been lost to subsequent follow-up. However, when last seen, all were in excellent condition. A soft diastolic murmur of pulmonary regurgitation was heard in one of these three (case 6), and a grade $2 / 6$ ejection systolic murmur was heard along the left sternal border in all. The murmur was, however, softer than before operation.

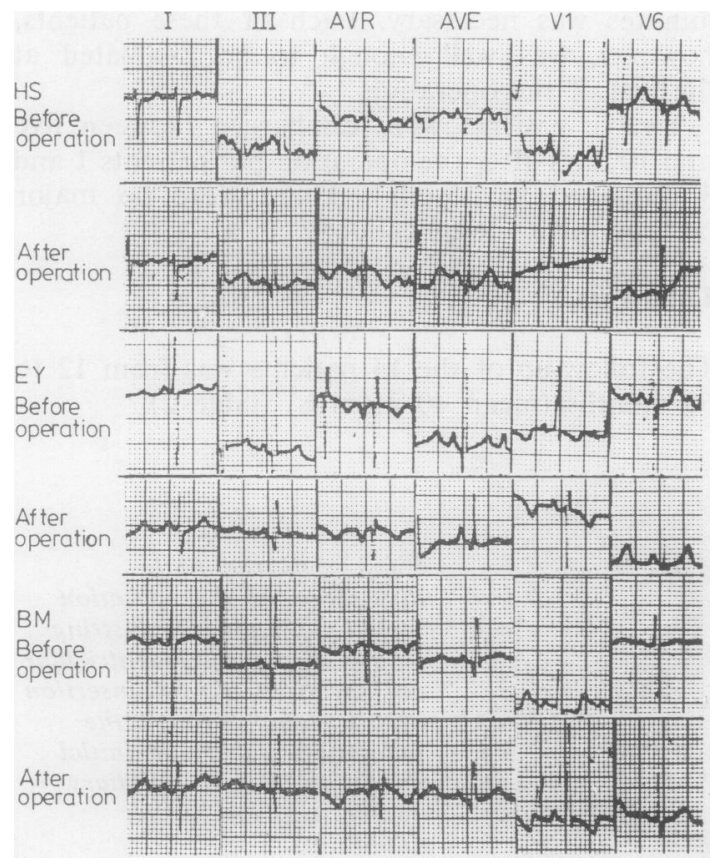

Fig 2 Preoperative and postoperative ECG recordings of three patients showing some regression of the right ventricular hypertrophy.
In two of the remaining 11 patients (cases $1 \Phi$ and 3) severe right ventricular hypertrophy per-응 sisted during the 12 months after operation. $\stackrel{\mathbb{}}{-}$ These two patients underwent catheterisation and $\overrightarrow{0}$ the right ventricular pressures were $100 \mathrm{mmHg}$ and $120 \mathrm{mmHg}$ respectively. They are both doing well five and four years after operation, but are awaiting further surgical treatment.

In the remaining nine cases, there was noo electrocardiographic progression but rather $a \frac{}{\mathbb{Q}}$ tendency to regression of the right ventricular hypertrophy (fig 2), and in three patients, a rightō ventricular hypertrophy (fig 2), and in three 3 patients, a right ventricular strain pattern which had been present before the operation, disappeared. Each of these patients is in excellent condition. In all patients a systolic murmuro usually grade $2 / 6$ and ejection in quality was ${ }^{\times}$ heard along the left sternal border. In one patient 3 (case 3) a diastolic murmur of pulmonary regurgitation was heard. The electrocardiogram, however, did not reveal signs of volume overload of the right ventricle. There are no signs of congestive cardiac failure in any of the patients. $\frac{D}{O}$

In patients in whom congestive cardiac failure and cardiomegaly was present before the ${ }_{O}^{N}$ operation (cases $3,6,7,11$ ) postoperative radiographs usually showed a decrease in cardiac N size (fig 3).

\section{Discussion}

Despite the simplicity of the lesion in pulmonary? stenosis and of the surgical treatment the operative mortality in the infant group is high. $\frac{\overrightarrow{\mathbb{D}}}{\mathrm{O}}$ Danielson et $a l^{2}$ reported three deaths in 14 ? infants $(21 \%)$. Gersony et $a l^{3}$ reported five deaths $\varrho$ out of 19 cases $(26 \%)$, and Mistrot et $a l^{4}$ two out of 12 cases $(16 \%)$. Of 16 patients who were 


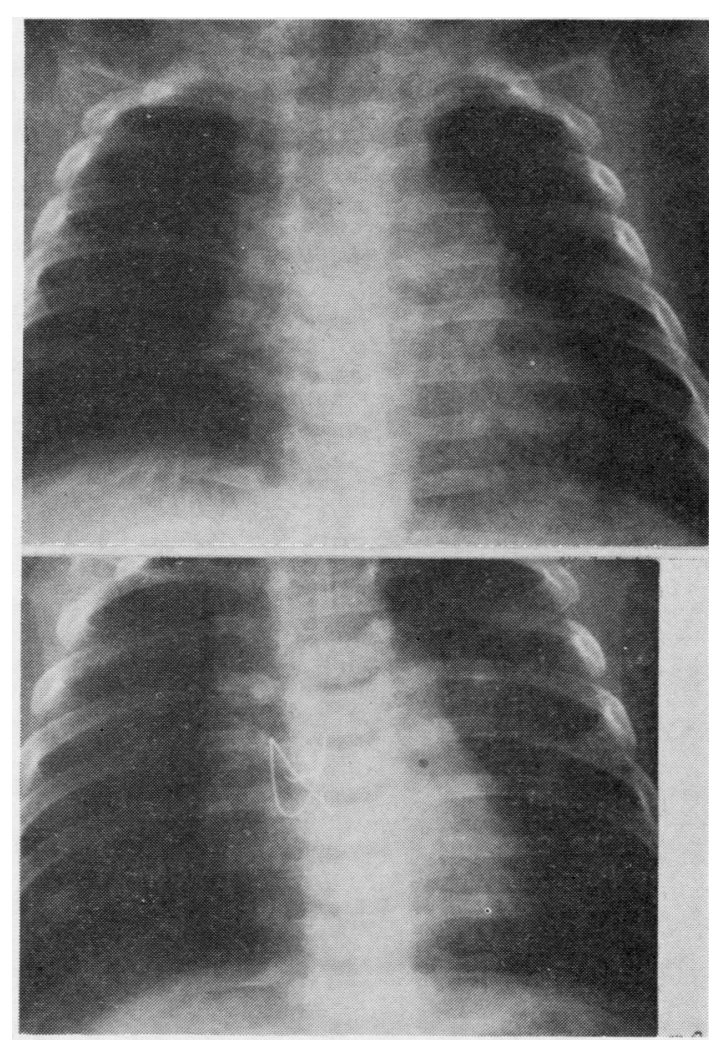

Fig 3 Preoperative and postoperative chest radiographs in a patient who had preoperative cardiomegaly showing the postoperative decrease in cardiac size. Top before, bottom after operation.

operated on in a hyperbaric chamber, six survived. $^{3} 5$

In our opinion, the critical factors contributing to the high survival rate in the present group are as follows: (1) maximum oxygenation during surgery and constant vigorous ventilation with $100 \%$ oxygen; (2) treatment of bradycardia by immediate administration of isoprenaline and sodium bicarbonate, and of blood loss by blood replacement by immediate injection via a central venous line; (3) rapid and adequate dilatation of the pulmonary valve, and an adequate operative exposure, without traction on the heart; and (4) earlier operation on patients with critical pulmonary stenosis, but on patients still in good clinical condition.

The incidence of pulmonary regurgitation in the group is also low. In the series of Gersony et $a l^{3}$ Mistrot et $a l,{ }^{4}$ and Talbert et al. ${ }^{6}$ the incidence is $50 \%$ or higher. The reason for the difference is probably the different technique which we have used. While in the original Brock technique $^{7}$ and in the technique of inflow occlusion with transarterial valvotomy described by $\operatorname{Varco},{ }^{8}$ the valve was sharply incised, in the present technique no sharp instruments are used and it is probable that the fused commissures are disengaged along optimal lines.

In two patients early in the series (cases 1 and 3 ) residual pulmonary stenosis is present. In both, the difficult postoperative course and other clinical data indicate that the stenosis results from inadequate valvotomy and is not re-stenosis. However, as stressed elsewhere, the operative technique was subsequently changed, with better results. In none of the remaining cases was there clinical evidence for the development of new stenosis after the initial valvotomy. Followup periods, however, are short, and long-term conclusions cannot yet be drawn. We have not recatheterised most of the patients and it is possible that residual pulmonary valve abnormalities may be present. If so, they are mild.

Although it may be expected that valvotomy under direct vision, using cardiopulmonary bypass, hypothermia, or temporary inflow occlusion, should be a better approach, this apparently is not the case. Temporary occlusion does not allow enough time for achieving a dry operative field, particularly in small infants, where a suction tip cannot be introduced via the small orifice of the stenotic valve into the right ventricle. Consequently, incision of the commissures must be made hastily, usually not exactly along the commissural lines and, therefore, missing the point of achieving an accurate valvotomy. Moreover, in small children, even with the aid of open-heart procedures, it is time consuming to achieve a perfectly dry field and rarely, in our experience, can one obtain perfect incision along the fused commissures.

Critical pulmonary stenosis in infancy carries a constant threat of sudden death, as indicated by Keith et al, ${ }^{9}$ Levine et $a l,{ }^{10}$ and Wurzel et al. ${ }^{11}$ If the operative risk is low, as in the present series, we recommend that the indications for surgery should be more liberal and that valvotomy should be performed in infants under the following circumstances: (1) cyanosis; (2) congestive heart failure; (3) electrocardiographic ippearance of important right ventricular strain; (4) the appearance of severe radiographic cardiomegaly; (5) the presence of right ventricular pressure higher than svstemic pressure. 


\section{References}

1 Brock RC. Pulmonary valvotomy for relief of congenital pulmonary stenosis: report of three cases. Br Med J 1948; 1:1121-6.

2 Danielson GK, Exarhos ND, Weidman WH, McGoon DC. Pulmonic stenosis with intact ventricular septum. Surgical considerations and results of operation. $J$ Thorac Cardiovasc Surg 1971; 61:228-34.

3 Gersony WN, Bernhard WE, Nadas AS, Gross RE. Diagnosis and surgical treatment of infants with critical pulmonary outflow obstruction. Circulation 1967; 35:765-76.

4 Mistrot J, Neal W, Lyons G et al. Pulmonary valvulotomy under inflow stasis for isolated pulmonary stenosis. Ann Thorac Surg 1976; 21: 30-7.

5 Litwin BS, Williams WH, Freed MD, Bernhard WF. Critical pulmonary stenosis in infants: a surgical emergency. Surgery 1973; 74:880-6.

6 Talbert LL, Morrow AG, Collins NP, Gilbert $\frac{\bar{\partial}}{\bar{c}}$ $\mathrm{JW}$. Incidence and significance of pulmonic $\vec{\varnothing}$ regurgitation after pulmonary valvotomy. $A m \propto$ Heart J 1963; 65:590-6.

7 Brock RC, Campbell M. Valvotomy for pul- $\vec{\circ}$ monary valve stenosis. Br Heart $J$ 1950; 12:377-802.

8 Varco RL. In discussion of Muller WH Jr. The surgical treatment of cardiac valvular stenosis. $\vec{x}$ Surgery 1951; 30:41-2.

9 Keith JD, Rowe RD, Vlad P. Heart diseases in infancy and childhood. Second edition. New York: Macmillan, 1967; 543.

10 Levine OR, Blumenthal S. Pulmonic stenosis. Circulation 1965; 32: Suppl IIII, 33-41.

11 Wurzel M, Aygen M, Elian E, Glaser J. Criticalpulmonic stenosis in infancy. Harefuah 1977; 93: 283-5. 